\title{
La Historia que debía enseñarse durante la última dictadura militar en Argentina (1976- 1983)
}

\author{
History that was taught during the last military dictatorship in \\ Argentina (1976 - 1983)
}

\author{
Laura Graciela Rodriguez*
}

\begin{abstract}
RESUMO
El 24 de marzo de 1976, los integrantes de las tres Fuerzas Armadas en Argentina organizaron el sexto asalto a un gobierno elegido constitucionalmente, al tiempo que se habían sucedido otros golpes de Estado de similares características en los países del Cono Sur Latinoamericano (Paraguay, Brasil, Chile y Uruguay). En comparación, la última dictadura militar argentina fue la más cruenta de la región, dejó un saldo de 30 mil "desaparecidos", entre los que se encontraban cientos de estudiantes y docentes.

Es sabido que las autoridades educativas de un gobierno determinado buscan transmitir un relato de la Historia escolar que esté acorde con sus proyectos políticos. En este artículo analizaremos qué hechos y personajes de la Historia nacional fueron introducidos por los funcionarios del Ministerio de Educación de la provincia de Buenos Aires durante esos años (1976-1983). A través del estudio de la normativa destinada a modificar el "calendario escolar" que producían los ministros de educación y subsecretarias/os, identificaremos qué continuidades y rupturas se establecieron con el período anterior (1973-1976), qué celebraciones y actividades se incluyeron y el tipo de nociones del pasado que se buscó transmitir.
\end{abstract}

PALAVRAS-CHAVE: Educación y Dictadura; En- KEYWORDS: Education and Dictatorship-eduseñanza de la Historia; Calendario Escolar; cation of History; Scholastic Calendar: Military Dictadura Militar; Usos del Pasado; Argentina. Dictatorship: Uses of the Past; Argentina.

\section{ABSTRACT}

The 24 of March of 1976, the members of the Army Force in Argentina, organized the sixth attack against the democratic government, at the same time that happen another dictatorships characteristic in the countries of the Latin American South (Paraguay, Brasil, Chile and Uruguay). In comparison, the last Argentine military dictatorship was most bloody of the region, left a balance of 30 thousand "disappear", between which were hundreds of tie people to the educative area.

It is known that the educative authorities of a certain government look for to transmit a story of the scholastic History that is agreed with its political projects. In this article we will analyze what facts and personages of History were introduced by the ministers of the Ministry of Education of the province of Buenos Aires during those years (1976 - 1983). Through study of the norm destined to modify the "scholastic calendar" that produced the ministers of education and their collaborators, we will identify what continuities and ruptures settled down with previous the Peronist period (1973-1976), what celebrations and activities included and the type of slight knowledge of the past that looked for to transmit.

El 24 de marzo de 1976 los integrantes de las tres Fuerzas Armadas

\footnotetext{
Doutora em Antropologia Social (UNaM). Professora da Universidad Nacional de La Plata (UNLP) e pesquisadora do CONICET na Universidad Nacional de General Sarmiento (UNGS) / Argentina.
} 
(Ejército, Armada y Aeronáutica) organizaron el sexto asalto a un gobierno elegido constitucionalmente, al tiempo que se habían sucedido otros golpes de Estado de similares características en los países del Cono Sur Latinoamericano (Paraguay, Brasil, Chile y Uruguay). En comparación, la última dictadura militar en Argentina fue la más cruenta de la región. Los organismos de derechos humanos calculan que hubo alrededor de 30 mil "desaparecidos", denominación que define a las personas que fueron secuestradas por las fuerzas de seguridad y de las que no se supo el paradero durante mucho tiempo. Lo cierto es que la mayoría fue torturada en aproximadamente 340 centros clandestinos de detención distribuidos en todo el país y/o asesinada. Esta investigación se inscribe en el conjunto de trabajos sobre la historia reciente argentina que tienen estos hechos como marco de referencia general (FRANCO y LEVÍN, 2007).

Es sabido que las autoridades educativas de un gobierno determinado y especialmente de uno autoritario, buscan transmitir un relato de la Historia escolar que esté acorde con sus proyectos políticos, seleccionando y omitiendo ciertos sucesos y personajes. Existen numerosas investigaciones de distintos países que describen cómo se ha realizado esta operación en los manuales escolares (FERRO, 1981; CARRETERO, 2007; VALLS, 2008; y DE AMÉZOLA, 2008). Los gobernantes tienen la preocupación de “inventar" una tradición particular en donde puedan ellos mismos incluirse en esa "comunidad imaginada” nacional (ANDERSON, 1993; y HOBSBAWM y RANGER, 2002). A lo largo del siglo XX los países latinoamericanos y particularmente los del Cono Sur pasaron por regímenes democráticos de distinto tipo que se alternaron con golpes militares. En Argentina, todos ellos pretendieron introducir en la escuela una serie de cambios en el relato de la Historia que gozaron de distintos grados de eficacia.

Los investigadores de esta temática han hecho foco en la reforma curricular de diciembre de 1978, que afectó a los primeros años de los colegios secundarios nacionales. Observando las materias de Historia y Formación Moral y Cívica, los analistas mostraron cómo se profundizó el sesgo nacionalista y católico en los nuevos contenidos (ROMERO, 2004; KAUFMANN, 2006; KAUFMANN y DOVAL, 2006; y ALONSO, 2007). En este trabajo nos detendremos en el examen de una fuente poco vista por los estudiosos del 
período, como es la normativa -circulares, directivas y resoluciones ministeriales- producida para el "calendario escolar" de la provincia más grande del país, Buenos Aires. En el calendario escolar los ministros de educación argentinos hacían saber qué fechas y personalidades debían recordarse ese año, cómo tenían que organizarse los "actos patrios" y todo lo referido a la organización escolar (día de inicio del ciclo lectivo, semanas de exámenes, entre otros). En los años del autodenominado Proceso de Reorganización Nacional, las autoridades estaban habilitadas para incorporar, por fuera de lo dispuesto a principios de año, otros sucesos que consideraran relevantes (las “conmemoraciones” o “celebraciones”).

En este artículo analizaremos qué hechos y personalidades de la Historia fueron introducidos en el calendario escolar por los funcionarios del Ministerio de Educación de la provincia de Buenos Aires durante esos años (1976-1983). A través del estudio de la normativa destinada a intervenir en el calendario, identificaremos el tipo de nociones del pasado que buscaron transmitir, las organizaciones con las que se relacionaban y qué serie de actividades se incluyeron para los docentes. La hipótesis central que recorre todo el trabajo es que las intervenciones en el calendario tuvieron el objetivo de legitimar las acciones y las alianzas presentes del gobierno dictatorial, vinculadas a un proyecto más amplio que consistía en liberalizar la economía; desarticular el Estado intervencionista (cuyo principal promotor había sido el peronismo); y lograr el disciplinamiento social por medio de la represión, que fue avalada por la conducción de la Iglesia Católica (QUIROGA, 2004; y NOVARO y PALERMO, 2003).

Más específicamente argumentaremos, en primer lugar, que las autoridades dictatoriales buscaron re escribir el pasado para borrar definitivamente la mención del general Perón y lo asociado al "populismo” o el “caudillismo". ${ }^{1}$ En segundo término, reforzaron los valores inscriptos en la

\footnotetext{
1 El general Juan Domingo Perón fue presidente elegido democráticamente entre 1945 y 1955, cuando un golpe militar interrumpió su mandato y lo mantuvo proscripto durante 18 años. En marzo de 1973 se volvieron a organizar elecciones libres y ganó el Partido Justicialista con Héctor Cámpora a la cabeza. En septiembre Perón fue habilitado a presentarse en los comicios, convirtiéndose por tercera vez en presidente constitucional. Perón murió en julio de 1974 y continuó su mandato la viuda, María Estela Martínez, quien se apoyó en el entonces ministro de bienestar social, José Lopez Rega quien encabezaba una organización denominada "Triple A" (Alianza Anticomunista Argentina) que se dedicó a perseguir y asesinar a militantes disidentes. En el medio de una crisis económica profunda y el crecimiento de los grupos armados de izquierda, una coalición civil y militar organizó un nuevo y último golpe militar.
} 
tradición católica, partiendo de una idea jerárquica de la familia, la sociedad y la política. Señalaremos cómo ciertos personajes, que en su época habían hecho público su laicismo, ahora se encontraban en los contenidos escolares convertidos en fervientes católicos, como San Martín. Por último, veremos de qué manera pretendieron construir un pasado que justificara el accionar de las Fuerzas Armadas y en especial de un sector del Ejército, en relación con el conflicto bélico planteado con Chile, la política represiva hacia los "subversivos" y la aceptación del plan económico vigente. Mostraremos que en esta tarea el ministro de educación no estaba solo, ya que estableció alianzas con personas e instituciones del ámbito público y privado de nivel nacional y provincial, que fueron las responsables de los documentos que se dieron a leer en las escuelas. Estas fueron, entre otras, el Arzobispado de la Iglesia Católica de La Plata, la Secretaría de Información Pública o SIP de la nación, el mismo Ministerio de nación, el Instituto de Cultura Hispánica de la provincia de Santa Fe, la Liga Pro Comportamiento Humano, la Fundación Rizzutto, asociaciones sanmartinianas y de alemanes. Todas ellas eran afines ideológicamente, justificaron el golpe y la "lucha" contra la "infiltración marxista".

Ahora bien, estas ideas se correspondían con el perfil de los funcionarios que tuvo el Estado dictatorial. Entre 1976 y 1983, en la provincia de Buenos Aires hubo cinco ministros de educación (RODRÍGUEZ, 2009). El día 13 de abril el gobernador Saint Jean (1976-1981) nombró en el cargo al general de brigada (retirado) Ovidio Jesús Antonio Solari, quien permaneció desde 1976 hasta septiembre de 1980. El ministro Solari fue el único que consiguió diseñar una serie de reformas al sistema, ya que entre fines de 1980 y octubre de 1983 se sucedieron cuatro mandatarios de educación civiles que no llegaron a articular ningún proyecto propio en un contexto de crisis política y económica que se acentuaba. El general Solari pertenecía al grupo del Ejército cercano al presidente de facto, el teniente general Jorge Rafael Videla (1976-1981). Estaban a favor de la represión, apoyaron al ministro de economía José Martínez de Hoz (1976-1981), propiciaban una apertura democrática en el muy largo plazo y sostenían una idea elitista de la participación política (QUIROGA, 2004; y NOVARO y PALERMO, 2003).

Este artículo está estructurado en cinco apartados ordenados cronológicamente. El primero se refiere a la conformación de un nuevo 
calendario escolar; el segundo a los eventos que se sumaron en 1978 y el tercero a los organizados alrededor de la figura de San Martín. En la cuarta sección describiremos la construcción de los "centenarios” (de la inmigración, de la “conquista del desierto" y de la "generación del '80"). Finalmente, desarrollaremos las últimas actividades que se organizaron entre 1980 y 1983.

\section{La enseñanza de la Historia y el calendario escolar}

Con el nacimiento del sistema de enseñanza pública a fines del siglo XIX y principios del XX los historiadores de la denominada "Nueva Escuela Histórica Argentina" fueron los que escribieron la primera versión de la historia argentina que debía transmitirse en las escuelas. La idea que articulaba este relato original era que la nación preexistía al Estado y era un sujeto protagónico del devenir histórico que se ubicaba en un territorio que había sido desde siempre "argentino" (ROMERO, 2004; y BERTONI, 2001). Las autoridades construyeron un "calendario escolar" adonde impusieron las "efemérides patrias" que estaban ligadas al período independentista y debían recordarse en actos especiales. ${ }^{2} \mathrm{Al}$ calor de la crisis económica y el golpe militar de 1930 se creó otra escuela llamada "revisionismo" que se declaraba contraria a esta versión liberal. Los revisionistas plantearon dos cuestiones centrales: la relectura positiva del legado hispánico-católico y la identificación del "enemigo" en Gran Bretaña; y el rescate de la figura de los caudillos y en particular de Juan Manuel de Rosas (QUATTROCCHI-WOISSON, 1995; y SVAMPA, 1994).3 Años

2 Las "efemérides patrias" argentinas más importantes son seis: 25 de mayo (Día de la Revolución de Mayo de 1810); 20 de junio (Día de la Bandera por el día de la muerte de su creador, Manuel Belgrano); el 9 de julio (Día de la Declaración de la Independencia en 1816); el 17 de agosto (Día del Libertador General José de San Martín, se conmemora su muerte); el 11 de septiembre (Día del Maestro, se recuerda la muerte del educador y ex presidente Domingo F. Sarmiento) y el 12 de octubre (Día de la Raza o la llegada del Cristóbal Colón al Continente Americano). Buena parte de ellas fue establecida por los gobiernos surgidos en elecciones fraudulentas que se sucedieron entre 1930 y 1940, que favorecieron la presencia de una perspectiva autoritaria, defensiva y excluyente del pasado y ligada a los principios católicos. (de Amézola, 2008).

3 Juan Manuel de Rosas era un poderoso ganadero que resultó gobernador de la provincia de Buenos Aires por dos períodos entre 1829 y 1852. Fue uno de los hombres con más peso en la política nacional durante esos años. En Argentina, su figura ha sido extremadamente controversial, para unos fue un "caudillo" autoritario que "arrastraba" a los gauchos ignorantes que lo seguían. Sanguinario con sus enemigos, representaba el "atraso" y lo peor del tradicionalismo. De manera contraria, sus defensores lo creían un "caudillo" en un sentido positivo, como representante de las "masas populares" y representante de sus intereses. Vale decir que la historiografía liberal había incorporado la figura de Rosas, reconociéndole principalmente el papel que desempeñó en la batalla de la Vuelta de Obligado frente a los 
después, el general Juan Domingo Perón fue presidente entre 1946 y 1955, y su gestión estuvo marcada por el objetivo de "peronizar" a la sociedad a través del sistema educativo, siguiendo la versión escolar de la Nueva Escuela (PLOTKIN, 1994; y DE AMÉZOLA, 1996). En 1955, Perón fue derrocado por los militares que prohibieron todo lo relacionado con el general y sus líderes, borrando sus nombres de los materiales escolares y del calendario escolar. Además, hicieron el esfuerzo de ligar al peronismo con el revisionismo histórico y particularmente con el "rosismo" y el "caudillismo", estigmatizando a ambos (HALPERÍN DONGHI, 1971).

Perón y su movimiento estuvieron proscriptos durante 18 años hasta que los militares en el poder, inmersos en una profunda crisis de gobernabilidad, debieron admitir que era necesario habilitar su vuelta a la escena pública. Durante ese tiempo, el ex-presidente encontró en la interpretación revisionista una explicación del pasado que le era funcional con su situación de exiliado. El revisionismo mutó así en una corriente heterogénea adonde convivían rosistas peronistas y antiperonistas (CATTARUZZA, 2003). El general Perón volvió a ser electo para la presidencia en septiembre de 1973 y sus aliados políticos incorporaron al sistema educativo la recordación de las fechas adonde era protagonista, asociándolo, esta vez de manera explícita, a las figuras de los caudillos federales y de Rosas, en un marco latinoamericanista y cristiano. El ministro de educación de la provincia de Buenos Aires hizo publicar en 1973 una "circular general" que ordenaba omitir y desautorizar los contenidos y términos que en los planes, programas y textos de estudio, calificaban negativamente a los períodos históricos de 1830 a 1852 y de 1943 a 1955 (C. N 124/74).4

En el calendario escolar se incorporaron fechas como la recordación de la muerte de Juan Manuel de Rosas, la Campaña al Desierto y la Defensa de Nuestra Soberanía (14 de marzo); el Día de los Caudillos, que recordaba a Estanislao López, "Pancho" Ramírez, Martín Güemes, Facundo Quiroga, “Chacho" Peñaloza, Felipe Varela y Gervasio Artigas y la "firma de la alianza ofensiva-defensiva de las Provincias Unidas contra la Presidencia de Rivadavia

bloqueos anglofranceses y erigiéndolo en defensor de la soberanía nacional ante las pretensiones extranjeras.

4 Las siglas "C."; "D." y "RM" indican el tipo de normativa producida dentro el Ministerio de Educación de la provincia y que era firmada por los ministros o subsecretarios/as: "circulares", "directivas" y "resoluciones ministeriales", respectivamente. 
en 1827" (17 de mayo). En julio comenzaba la Semana de la Independencia Política y Económica-Nacionalización de nuestra economía, que finalizaba el 8 con el Acto a la Independencia Nacional y el 9 con el feriado. El 8 de septiembre se había incluido el Día de los Derechos Civiles de la Mujer y se resaltaba la acción de la mujer argentina, dedicándole a la clase una hora de duración en séptimo grado. $5 \mathrm{El} 17$ de octubre recordaba el Día de la Lealtad Popular, que era "la jornada que en el año 1945 viviera el pueblo argentino, irrumpiendo definitivamente en el quehacer político del país la clase trabajadora”. El 10 de septiembre el Día del Trabajador de la Educación. En abril se dispuso celebrar el Día del Aborigen resaltando la figura del inca Tupac Amaru y la conmemoración en octubre del El Pacto Andino, adonde había que destacar los lazos de fraternidad que nos unían a los pueblos de Latinoamérica. Del 14 al 20 de noviembre se había dispuesto por primera vez la recordación de la Semana de la Soberanía Nacional, que englobaba dos acontecimientos: el día del combate de la Vuelta de Obligado y el fusilamiento del "caudillo" Dorrego (decreto $\mathrm{N}^{\circ} 4219$, 1973). El peronismo propuso esa fecha para reivindicar la obra realizada por el movimiento revisionista en la Argentina.

A partir de marzo de 1976 se inició una nueva etapa de "desperonización” de la sociedad en general y de la escuela en particular. Esta vez se asociaba el "revisionismo" al "marxismo" y, sin nombrarlo, al "peronismo". Desde ese año, el Calendario Escolar Único se elaboraba en el seno del Consejo Federal, que era la reunión de todos los ministros provinciales y encargados del área educativa del país. En la primera Asamblea realizada en mayo de 1976 el Consejo Federal dispuso por Ley $\mathrm{N}^{\circ} 21.329$ que se redujeran a ocho el total de feriados nacionales y a dos los días considerados no laborales. La iniciativa pretendía "incrementar la productividad" aumentando los días de clase. Con el aval de la Iglesia, se habían eliminado del calendario nacional varias festividades católicas previstas en el decreto N $^{\circ} 2446$ del año 1956 (Asunción de la Santísima Virgen, Corpus Christi, Día del Sumo Pontífice y Día de Todos los Santos) y las fechas que se habían introducido durante el gobierno peronista. De acuerdo a la nueva norma, los días no laborables eran el jueves santo y el 8 de diciembre, Día de la Inmaculada Concepción. Los feriados nacionales quedaron en: 1 de enero,

$5 \quad$ Esta fecha recordaba el día 8 de septiembre de 1947 cuando se sancionó la ley 13.010 por la cual el presidente Perón y su esposa Eva Duarte le dieron el voto a las mujeres. 
viernes santo, 1 mayo, 25 de mayo, 20 de junio, 9 de julio, 17 de agosto y 25 diciembre.

En la provincia de Buenos Aires el ministro de educación Solari anunció a través de la prensa que había introducido modificaciones al calendario escolar que tenían por objeto reforzar y enfatizar el sentido de moralidad, resaltando valores cristianos, de la tradición nacional y de la dignidad del ser argentino. Al igual que a nivel nacional, borró todas las fechas que habían sido creadas por el peronismo y aclaró que se eliminaban también el Día de la Campaña del Desierto y el Día de los Caudillos y se reemplazaban por el Día de las Campañas del Desierto y el Día del Federalismo. De este modo, decía, se recordaban "todas las campañas" y se brindaba "una síntesis del anhelo de integración nacional que inspiró a los líderes regionales de nuestra patria”. Además, conservó la Semana de la Soberanía pero sin el "fusilamiento de Dorrego", cambiándole completamente el sentido original dado por el peronismo.

En línea con esto, el gobernador Saint Jean dio una conferencia denominada la "Educación y el futuro" adonde se dedicaba a oponer, de un lado, las figuras de Rosas y Perón calificándolos de "caudillos" y "demagogos"; y del otro, al "hombre" "fuerte" "viril" y "conductor" que vendrían a ser él mismo y los funcionarios que lo acompañaban. En este esquema, la educación debía servir para "evitar" la "reaparición del caudillo":

\begin{abstract}
Sólo por medio de una educación formadora evitaremos la reaparición del caudillo; no del auténtico hombre fuerte, seguido por sus hombres por sus condiciones viriles y de conductor, sino del actual, del caudillo de la sociedad de masas; ese showman moderno, gesticulador y teatral que posee un dominio total sobre su público siempre en la forma más degradada: la multitud indiferenciada, sin rostro, entregada dócilmente a reaccionar de acuerdo a los hábiles estímulos aplicados por el dictador de turno" (Revista de Educación y Cultura. Ene- febmar. 1978. Año 3, N 1. La Plata, Buenos Aires, pp. 15-6.).
\end{abstract}

Junto a esto, existió una política de eliminar de los establecimientos educativos los nombres de Perón y los relacionados con el peronismo. El 17 de octubre de 1973 el peronismo bonaerense había dispuesto en el Reglamento General de Escuelas Públicas que podían ponerse denominaciones a las escuelas de personas que aún estuviesen vivas y bautizaron a varias con el nombre de "General Perón”. En noviembre de 1976 se derogó por decreto la modificación a ese artículo. La norma volvía a la original de 1958 que dictaminaba que tenía que esperarse por lo menos diez años de fallecida una persona para poder usar su nombre. El decreto facultaba al Ministerio a revisar todas las asignaciones 
que se habían realizado. Así, los ministros de la dictadura se dedicaron a reemplazar las anteriores designaciones peronistas por nombres relacionados al ámbito castrense. Las escuelas y jardines pasaron a llamarse "Policía Federal"; "Armada Argentina”; "Escuadrón de Ingenieros Blindado I”; “Teniente de Navío Melchor Escola", "Fragata Libertad", entre otros.

Volviendo al calendario escolar, analizaremos de ahora en adelante cuáles "celebraciones" o "conmemoraciones" fueron agregadas a lo largo del período dictatorial y qué tipo de actividades debían realizar los docentes con sus alumnos, que eran indicativas de la importancia otorgada al evento (por ejemplo, una o varias clases alusivas, lectura de documentos, lecciones paseo, visita a museos, concursos). Según el organigrama del Ministerio, la Subsecretaría de Educación tenía a su cargo todo lo relacionado con el funcionamiento de las escuelas, por lo que el ministro la facultaba a disponer "la celebración o conmemoración de cualquier acontecimiento que lo reclame y que no se encuentre contemplado en el Calendario aprobado". La mayoría de los documentos que citaremos fueron firmados por la subsecretaria en ese momento, Josefina Alonso de Dumrauf (1977-1979). Dumrauf había nacido en Bahía Blanca, era maestra normal, profesora en el Instituto de Formación Docente e Inspectora de Enseñanza Primaria desde 1970. El circuito administrativo era el siguiente: ella enviaba sus directivas a los inspectores regionales, quienes tenían a su cargo una "región educativa" que comprendía varios municipios (Rodríguez, 2009). Cada uno debía darlas a conocer en todos los establecimientos de su región y eran los máximos responsables de que se cumplieran. Si se constataba que un docente no había implementado la actividad en el aula, podía recibir una sanción que iba desde un “apercibimiento" hasta el "inicio de un sumario administrativo".

\section{Las conmemoraciones de 1978. La defensa de "la familia" y de la soberanía: el "enemigo" chileno.}

En el año 1977 registramos una sola conmemoración organizada por la Subsecretaría de Educación que delataba la relación estrecha que tuvo el sector jerárquico de la Iglesia Católica con la dictadura. En mayo, el encargado del área ordenaba que en las escuelas se diera lectura al mensaje completo del Arzobispo 
de La Plata, Antonio José Plaza sobre "sus patrióticas reflexiones con motivo de las próximas fiestas mayas", para que fueran "motivo de lectura, análisis y comentarios por parte del personal directivo y docente de las Unidades Escolares de todos los niveles y modalidades de la enseñanza". ${ }^{6}$ El mensaje advertía que "nuestra pacífica y querida ciudad de La Plata", fue "escogida por los enemigos de la Patria en los presentes tiempos para sede de sus satánicos planes y de su accionar apátrida". Estos "malos argentinos" se concentraron en la Universidad, que era "cuna y foco de la guerrilla organizada". (D. $\mathrm{N}^{\circ} 10,18$ mayo 1977).

$\mathrm{Si}$ analizamos la serie completa de las conmemoraciones vemos que la mayor cantidad de intervenciones al calendario escolar se hicieron en 1978. Esto fue así porque desde el año anterior, los organismos internacionales se habían hecho eco de las numerosas denuncias sobre la existencia de censura en la prensa y de miles de detenidos-desaparecidos en centros clandestinos de detención. En respuesta, la Junta Militar diseñó distintas acciones destinadas a mejorar la imagen del régimen, tanto en el exterior como en el país. En el frente interno, gastó una gran cantidad de recursos, utilizó todos los medios de comunicación a su disposición y consideró a la escuela un espacio privilegiado para hacer llegar la propaganda procesista. Varios acontecimientos nacionales fueron llevados a las escuelas bonaerenses y de otras provincias: se declaró Año del Bicentenario del Nacimiento del General Don José de San Martín (que trataremos en el siguiente apartado); se hizo el Mundial de Fútbol; la Secretaría de Información Pública o SIP organizó "campañas nacionales” y se recordó de manera especial el Día del Comportamiento Humano. Sumado a esto, los militares provocaron un grave conflicto con Chile y utilizaron la escuela para justificar sus avanzadas bélicas.

En esta sección comentaremos, además de las tareas que debían organizar los docentes, el contenido de los documentos que tuvieron que leer los alumnos bonaerenses y algunas características de las organizaciones ligadas al ministro. Se distribuyeron textos que tenían en común la alusión a la familia que habían sido preparados por la SIP (derechos y obligaciones y la familia) y por la Liga de la Fundación Rizzuto (día del comportamiento humano). Los otros escritos

\footnotetext{
${ }^{6}$ Las "fiestas mayas" hacen referencia al Día del 25 de mayo de 1810, fecha en que se recuerda la formación del primer gobierno patrio.
} 
hablaban de la soberanía y fueron elaborados por la Subsecretaría (Mundial de Fútbol), el militar Rodríguez Zía del Instituto de Cultura Hispánica de Santa Fe (canal de Beagle) y la SIP (día de la tradición y día de la soberanía).

Las temáticas que abordaban estos documentos no eran novedosas y estaban presentes en los diseños curriculares y en los textos escolares de Historia, Geografía y Civismo que se leían en las escuelas entre 1950 y 1983 (ALONSO, 2007; DE PRIVITELLIO, 2004; QUINTERO, 2004; y ROMERO, 2004). Tempranamente propusieron un modelo del "hombre argentino" basado en el nacionalismo integrista, el neotomismo, y especialmente desde 1955, en las teorías del totalitarismo de la Guerra Fría y la Seguridad Nacional. La concepción neotomista aparecía en la caracterización del hombre, la familia y el municipio y eran consideradas instituciones naturales. Así, la familia era una metáfora de la nación, que era previa al Estado y se definía por su unidad católica. La democracia era presentada, no como un régimen político institucional, sino como el resultado de un "estilo de vida" amenazado por el enemigo externo (que podía ser el "comunismo" y el "terrorismo internacional") y el interno (la "subversión").7 La argentinidad se relacionaba con la soberanía y se denunciaban las múltiples formas de su violación, afirmando la necesidad de su defensa militante y cotidiana. Estas nociones típicas de los años de 1950 y 1960 se profundizaron durante la última dictadura, los currículos se hicieron más católicos y se reforzaron las cuestiones de los límites y la frontera en un registro geopolítico. En definitiva, la Junta Militar buscaba transmitir a los alumnos el mensaje que la nación (democrática, occidental y cristiana) se encontraba asediada y seriamente amenazada por estos "peligrosos" enemigos. Los militares, junto con la Iglesia católica habían llegado para refundar la nación.

La primera circular que firmó la subsecretaria Dumrauf fue de adhesión a la "campaña nacional" organizada por la SIP, denominada Derechos y

\footnotetext{
7 Estas ideas son parte del pensamiento de la "extrema derecha" o de los "contrarrevolucionarios", presente tanto en los países centrales como los de América Latina y que hunde sus raíces en el siglo XIX. Los representantes de la derecha (civiles o militares) se han opuesto en todas partes al liberalismo, la democracia, el feminismo y las variadas formas de izquierdismo, a quienes identifican como los responsables de la disolución de las jerarquías tradicionales, la destrucción de los vínculos personales, del orden social y del estilo de vida. Ellos promueven su visión de la sociedad a través del fortalecimiento de la familia, la moral, la religión, la autoridad, la propiedad, el racismo, el nacionalismo xenófobo y la subordinación a la nación como la más alta autoridad. (MCGEE DEUTSCH, 2003).
} 
Obligaciones. La SIP era un organismo que dependía de presidencia y formaba parte de una compleja y antigua trama de instituciones estatales dedicadas a controlar y censurar expresiones culturales (AVELLANEDA, 1985). Durante esos años fue utilizada como uno de los principales medios de propaganda. Uno de sus objetivos era "contribuir mediante la comunicación social a lograr que la población local y las áreas de decisión internacionales, adopten actitudes y conductas positivas de adhesión al Proceso de Reorganización Nacional”. ${ }^{8}$ En general, la SIP organizaba una campaña nacional sobre algún tema, escribía un documento con "ideas fuerzas" y lo mandaba a todas las provincias. Las dependencias educativas lo recibían para replicarlo y podían introducir adecuaciones. ${ }^{9}$ El objetivo general de la campaña era promover en la población el conocimiento de los deberes y de los derechos que le pertenecían "como integrante del mundo occidental y cristiano”. Teniendo en cuenta que el sistema educativo debía "conducir a la consolidación del orden social de la nación, atendiendo a las necesidades presentes y previsibles del individuo, la familia y la comunidad”, establecía que a partir de la iniciación del curso lectivo de 1978, en los establecimientos educativos de todos los niveles y modalidades se desarrollaran dos clases por semana durante todo el año. Las clases tenían que estar dedicadas al tratamiento de situaciones surgidas "del diario vivir" o extraídas de los medios de comunicación que permitieran a los educandos "vivenciar conductas y normas de vida" y analizar hechos en los que se pusiera de manifiesto "la importancia de una convivencia interpersonal y social armónica”. (D. N 10, 25 enero 1978).

En marzo, la Subsecretaría se adhirió a la conmemoración del Día del Comportamiento Humano (31 de marzo) organizada por la Liga Pro Comportamiento Humano. La circular de la Subsecretaría afirmaba que ese Día

\footnotetext{
8 La SIP contaba con una Subsecretaría de Planeamiento y una Dirección General de Inteligencia, cuyas funciones eran las de realizar el control de las emisiones de Radio y TV estatales, de la prensa nacional y de la prensa internacional "para controlar el contenido de los mensajes que se transmiten o imprimen, para desvirtuar los negativos o incrementar los positivos". El público al cual se dirigía esta "estrategia de comunicación social" aparecía clasificado en cuatro grupos: "los adherentes", los "indiferentes", los "no informados" y los "adversarios u oponentes". Sobre estos últimos iba dirigido el plan represivo. (INVERNIZZI y GOCIOL, 2002).

9 La última campaña de la SIP se realizó en julio de 1979 y planteaba trabajar en las escuelas la temática de la represa hidroeléctrica de Salto Grande, un emprendimiento que involucraba a la Argentina y Uruguay y había sido inaugurado en junio de 1979. Del mismo modo que con Brasil, los militares se preocuparon de no generar mayores conflictos con esos gobiernos, debido a los variados proyectos de generación de energía que sostenían con los dos.
} 
se exaltaban los "valores éticos, morales y espirituales" que conformaban "nuestro estilo de vida" y disponía que en todas las escuelas de la provincia se diera lectura al mensaje del señor Ministro de Educación. El mandatario advertía que se vivían tiempos en los que la violencia, la destrucción de personas y bienes y la desintegración de la familia eran problemas que afectaban a toda la sociedad y que ellos - los militares- venían a solucionar. Una vez dado a conocer el mensaje, los docentes en las aulas tenían que promover la reflexión de los alumnos con respecto a su contenido. (D. $\mathrm{N}^{\circ} 21,20$ marzo 1978).

Esta fecha existía en el calendario desde antes de 1976, pero con la dictadura cobró un nuevo impulso. Ese día se recordaba el fallecimiento de Francisco A. Rizzuto en 1965 quien fuera el fundador de la Liga, "una institución sin fines de lucro cuyos ideales eran difundir hermandad y respeto en la sociedad". Desde 1960 el presidente de la Liga era el hijo, Francisco "Pancho" Rizzuto, que en 1965 era además el vicepresidente de la Federación Argentina de Entidades Democráticas Anticomunistas (FAEDA), una agrupación nacionalista de derecha. La sede de la Fundación Rizzuto era frecuentada por militares, entre los que se encontraba el titular de la SIP, Rubén Franco, quien frente a las denuncias de censura dijo: "Rechazamos terminantemente las falsas acusaciones de quienes pretenden erigirse en nuestros inquisidores y de quienes, intimidados por el terrorismo internacional, permiten que la prensa sea utilizada como vehículo para tan bajos designios”. (El Día, 27 de septiembre de 1978, p. 5).

La campaña sobre La Familia de la SIP pretendía "revitalizar la función integradora que como célula primera de la sociedad le compete, en la consolidación de la paz y la unión de todos los individuos que conforman la Nación". (D. $\mathrm{N}^{\mathrm{o}}$ 35, 29 mayo 1978). La normativa ordenaba que en todos los establecimientos educacionales de nivel primario y medio debía dictarse una clase semanal -por un lapso aproximado de noventa días a partir de la notificación de la presente- en la que se tratarían las ideas fuerzas sugeridas por la SIP. Estas eran:

La familia posee proyección integradora y vital. La familia es grupo generador social. La familia es célula primera de la relación humana y por lo tanto única para simbolizar la idea de prójimo. La familia es escuela de valores morales, materiales y religiosos. La unión familiar es sustento de la unión nacional.

La investigadora Judith Filc (1997) señaló que la dictadura ubicó a la 
familia en la esfera pública, en tanto reflejo ampliado de una nación jerarquizada. Estas jerarquías se establecían en términos de clase, de género, étnicos y religiosos, adonde la ley y el orden estaban del lado del padre y por extensión de los hombres (blancos, heterosexuales, católicos tradicionales y de clase media y alta). En posición de subordinación se encontraban las mujeres, respetuosas de la autoridad y ubicadas en la esfera de lo doméstico en su rol de esposas y madres responsables de los menores de edad. Los alumnos y alumnas debían comprender que éste era el modelo de organización "natural" de la familia, cuyo origen era divino y su disolución equivalía al "caos" social vivido antes de marzo de 1976, cuando las "madres" descuidaron a sus hijos y cayeron en manos de la "guerrilla apátrida". Desde este razonamiento, la desintegración familiar era asociada a una estrategia comunista. Tal era la importancia de "la familia" que en diciembre de 1978 el ministro nacional presentó los nuevos contenidos de la materia "Formación Moral y Cívica" para el ciclo básico de la secundaria que contenía estas mismas definiciones.

El Mundial de Fútbol se realizó en Argentina a mediados de ese año y la Junta Militar aprovechó la importancia del evento para advertir a los alumnos que los "extranjeros" estaban cuestionando a la nación. En mayo la subsecretaria le pidió a los docentes que contribuyeran a "contrarrestar" la "campaña antiargentina" que se estaba viviendo: "Es este un momento de euforia que la escuela no puede desaprovechar. Por el contrario, la oportunidad exige la implementación de valiosas experiencias de aprendizaje que canalicen el entusiasmo e interés de los alumnos”. En este Campeonato no estaba sólo en juego un título deportivo, "sino el prestigio de un país y de un pueblo. El mundo nos mira, demostremos entonces que somos capaces de unir nuestras fuerzas en una empresa común y de actuar con verdadera vocación de servicio". (D. $\mathrm{N}^{\circ} 40$, 29 mayo 1978). La funcionaria les decía a profesores y maestros que procuraran "que cada uno de sus alumnos" tomara conciencia de estos hechos. Después del Campeonato tenían que evaluar "lo acontecido" adentro del país en función de "las actitudes que sus integrantes, público y pueblo" habían manifestado "durante su transcurso, dentro y fuera del estadio".

Otro de los posibles "enemigos" eran los vecinos de los países limítrofes y estas nociones se habían incorporado a los contenidos escolares desde 1950. Chile era caracterizado como un país que buscaba expandirse sobre la Patagonia 
y el Atlántico Sur, zonas que "desde siempre" habían sido argentinas. Entre mayo de 1977 y diciembre de 1978 las relaciones entre Argentina y Chile se fueron deteriorando aceleradamente a causa del conflicto por la zona del canal de Beagle (NOVARO y PALERMO, 2003). En este contexto, el gobernador bonaerense y sus colaboradores utilizaron el sistema educativo para justificar sus posiciones belicistas. En abril la Subsecretaría distribuyó en todas las escuelas un extenso documento del coronel Jorge L. Rodríguez Zía denominado "El Fallo del Beagle-De Mar a Mar". Rodríguez Zía fue uno de los fundadores del Instituto de Cultura Hispánica de la provincia de Santa Fe y era definido como un "soldado de acendrado nacionalismo y arraigado hispanismo". Era profesor de Historia de España en la Universidad Católica Argentina y asesor en temas de geopolítica.

En su texto, el coronel justificaba jurídicamente los reclamos de Argentina y se declaraba a favor de responder cualquier agresión en tierra o mar con la fuerza de las armas y a la "intrusión" de pobladores chilenos, con la expulsión inmediata de los mismos. En su parte histórica, el autor reescribía el pasado y clasificaba a los personajes de la historia entre quienes habían actuado "patrióticamente en las cuestiones de límites con Chile" y quienes no lo habían hecho. Cada maestro de la escuela primaria tenía que elaborar "guías de estudios" que promovieran la investigación y el trabajo creador en el aula. A los profesores de la secundaria les pidió que les dieran a los alumnos directamente el cuadernillo para que profundizaran sus conocimientos sobre el tema y elaboraran una síntesis coherente. (D. $\mathrm{N}^{\circ} 28,12$ abril 1978).

Hacia fin de año el problema con Chile se había agudizado y en noviembre la SIP organizó la campaña nacional por el Día de la Tradición, que hacía hincapié en "la necesidad de motivar a la población para que asuma con orgullo y entusiasmo nuestras tradiciones, a fin de reafirmar a través de ellas los sentimientos de soberanía y nacionalidad". En concordancia, la subsecretaria estimaba necesario dar mayor significación a la evocación para reafirmar nuestra "esencialidad como Nación". (C. N ${ }^{\circ} 58,1$ noviembre 1978). A partir del 6 de noviembre, los docentes debían publicar las frases de la SIP en la cartelera y en el periódico escolar y realizar clases especiales dedicadas a exaltar la obra de José Hernández; difundir las celebraciones tradicionales de distintas regiones de la provincia; impulsar la elaboración de trabajos monográficos 
sobre el tema "tradición y soberanía"; hacer comentarios de secciones literarias sobre obras de los autores de la época; visitar museos o lugares que recordaran "nuestras tradiciones"; y colaborar con el comercio local en la "ornamentación de vidrieras con motivos alegóricos". El mes de noviembre fue un mes de “festejos” corridos: después del Día de la Tradición, la SIP organizó el Día de la Soberanía Nacional. La campaña fue vinculada explícitamente con el conflicto chileno y la lucha contra la "subversión".

El ministro Solari había establecido en el calendario escolar conmemorar la "Semana" de la Soberanía Nacional y la Vuelta de Obligado. En una circular se determinaba que las escuelas debían: promover en cada establecimiento de enseñanza de todos los niveles y/o modalidades, tareas destinadas a "dar trascendente significado" a estas fechas; adoptar la guía orientadora del quehacer docente del Anexo confeccionado por la SIP; acopiar material periodístico que muestre "referencias concretas del momento actual"; y estimular la participación del alumnado en la realización de afiches, monografías, mesas redondas, paneles, seminarios, actividades de extensión bibliotecaria y en el periódico escolar. (C. $\mathrm{N}^{\circ}$ 59, 6 noviembre 1978). Estas producciones de los alumnos tenían que mostrar los "hechos de la defensa de la soberanía de nuestras aguas territoriales, la evolución del diferendo con Chile, la exigencia de la justa aplicación del derecho internacional para la inviolabilidad de nuestras fronteras y la lucha contra la subversión".

Las ideas fuerzas contenidas en el documento de la SIP establecían una analogía entre la Vuelta de Obligado y la actualidad: "Quienes atacan a la Argentina acusándola de violadora de los derechos humanos, sin reconocer su sacrificio espiritual y material para erradicar la subversión, mantienen idéntica posición que los agresores ingleses y franceses en aquella dura jornada". La SIP recomendaba llevar a cabo las siguientes acciones: "aprovechar la oportunidad para hacer entrega en todas las escuelas, pero sobre todo en las de frontera, de banderas y mapas de la zona antártica, mares argentinos e Islas Malvinas"; promover la participación de los alumnos primarios en el concurso "Soberanía Territorial Argentina, Prioridad Nacional". Por último, recordaba que "La Nación, digna heredera del valor de los héroes del combate de Obligado, no permitió ni lo hará, que apetencias foráneas mancillen su integridad moral y territorial”. 


\section{Los usos de los próceres: la figura de San Martín}

San Martín se había convertido desde los años de 1940 en el prócer máximo de la nacionalidad argentina, tanto para peronistas como para antiperonistas, historiadores liberales y revisionistas, democráticos y golpistas. ${ }^{10}$ San Martín era también el héroe preferido del general Videla (NOVARO y PALERMO, 2003). El año 1978 fue declarado Año del Bicentenario del nacimiento del Libertador General San Martín en todas las escuelas del país. Los funcionarios provinciales se ocuparon de establecer analogías entre las figuras de los militares de la Junta y San Martín, llegando a afirmar que éste luchaba, igual que ellos, contra la "subversión". Por su parte, la Iglesia se apropió de la figura de San Martín, un conocido militante de la masonería, e hizo circular el Mensaje de la Junta Arquidiocesana de la Acción Católica Argentina, que recuperaba "el sentido cristiano de San Martín", quien, según esta versión, era un "hombre de armas que confiaba en Dios".

En la provincia se creó la Comisión Provincial de Homenaje al Bicentenario presidida por el ministro de gobierno e integrada por los subsecretarios de educación, hacienda y asuntos municipales. Según el ministro, se buscaba "que el ejemplo del Libertador, nos guíe y enseñe en las horas difíciles que afronta la República". La Subsecretaría de Educación elaboró un "Calendario Sanmartiniano" y desplegó una intensa actividad todo ese año que difundía la figura del San Martín católico: en febrero invitó a todos los docentes a integrarse a los actos de homenaje a San Martín; autorizó a los alumnos a participar en programas de Radio y Televisión referidos a San Martín y organizó varios Seminarios de perfeccionamiento docente. Por una resolución ministerial se reconoció la Cátedra de Historia Sanmartiniana bajo la organización de la Asociación Cultural Sanmartiniana de La Plata; se organizó un plan de construcciones escolares; y se instituyó una beca con el nombre del prócer. Finalmente, el Ministerio de Educación de la provincia publicó un número especial en 1979 en homenaje al General San Martín. La revista estaba dedicada a informar sobre

\footnotetext{
10 José de San Martín (1778-1850) es considerado el máximo "héroe de la patria". Estuvo involucrado en los hechos de la independencia de 1816 y jugó un papel protagónico al frente del Ejército en la lucha contra los españoles, tanto en el actual territorio argentino como en los de Chile y Perú.
} 
las actividades del año anterior y publicaba los trabajos de alumnos y profesores que habían ganado el concurso provincial sobre su vida y obra.

Además, el ministro compró y repartió gratis 7.500 volúmenes de la obra "San Martín Educador", ganadora del Premio Rizzuto y escrita por el doctor Exequiel César Ortega, quien desde mayo de 1978 era el decano de la Facultad de Humanidades y Ciencias de la Educación de la Universidad Nacional de La Plata, ubicada en la capital provincial. Además de la mencionada obra, la Subsecretaría difundió dos trabajos más de Ortega, llamados "Cronología ideológica de San Martín” y "San Martín y la inflación”. A través de estos escritos, Ortega justificaba la idea del San Martín católico, el programa represivo de la Junta Militar y el plan del ministro de economía Martínez de Hoz, que pretendió recortar el gasto público y generó, entre otras cosas, un aumento sostenido de los precios durante todos esos años. ${ }^{11}$ En el primer documento, Ortega calificaba a San Martín de "liberal" y afirmaba que estaba "contra el extremismo, el terrorismo, el comunismo y el socialismo" porque despreciaban "el orden y la familia". En el segundo, el autor hacía una comparación entre la situación económica que le tocó vivir a San Martín y el contexto que se vivía en 1978. Planteaba que San Martín, estando en Europa, recibía un sueldo de Perú y algo por el alquiler de su casa en Buenos Aires, pero era víctima del "deterioro del papel moneda americano y de la inflación consiguiente", que se desvalorizaba "catastróficamente". Estas eran "alternativas y circunstancias que hoy conocemos de sobra", a tal punto que es "común que no cesemos de lamentarnos y condenar tanta inflación", tanto "papel moneda sin suficiente respaldo metálico (oro) que hace que, aparentemente, las cosas cuesten más". Los argentinos, ante la misma situación, en la actualidad se lamentan y condenan como "exclusivos culpables a los gobernantes, sobre los que aún decimos los consabidos 'tales y cuales”. (Revista Educación y Cultura. Año 4, 1979, pp. 140-41). Ortega se preguntaba “¿qué hizo en cambio San Martín entonces? San Martín no se lamentaba y se contentaba con lo que el gobierno podía dejarle”. Esta, según (Ortega) él mismo "no era una

11 El plan económico impuesto por Martínez de Hoz buscó reestructurar la economía en base a dos ejes: la apertura económica y la liberalización del mercado de capitales, bajo los principios de la subsidiariedad del Estado y la privatización de los servicios. Dicha política terminó desmantelando gran parte del sector industrial preexistente, dirigiendo la represión hacia los trabajadores afectados. (SCHVARZER, 1986). 
actitud común, ni en 1827 ni en 1978” (Ibidem). La moraleja era que los argentinos debían seguir el ejemplo del prócer y mantenerse en silencio frente a la escalada inflacionaria del momento.

El gobernador Saint Jean, en un discurso pronunciado por el bicentenario del nacimiento, el 25 de febrero de 1978, formuló una serie de comparaciones entre San Martín y el Proceso de Reorganización Nacional. Presentaba al libertador como religioso que se nutría de las "esencias pluriseculares que se remontan a la tradición cultural de Grecia, Roma y el Cristianismo". (Revista de Educación y Cultura. Año 3, No 1. 1978, pp 29-34). El gobernador y su grupo, igual que San Martín, se veían ahora "precisados a oponer nuestra réplica enérgica al terrorismo disolvente" en aras de defender "nuestra independencia". Las fuerzas armadas, "siguiendo su ejemplo, hoy estamos todos empeñados en restituir los valores esenciales que sirven de fundamento a la conducción integral del Estado, enfatizando el sentido de moralidad", promoviendo "la regeneración de nuestro sistema representativo, republicano y federal". San Martín, en varios de sus escritos "había manifestado su preocupación por las discordias internas y la anarquía". Saint Jean afirmaba que "hoy, nuestra generación tiene aún abiertas las heridas de un proceso de anarquía y decadencia que nos cubrió de vergüenza y nos llevó al borde de la disolución nacional". Terminaba haciendo una relación entre San Martín, la generación de 1880 y ellos. La generación del '8o fue "fiel" al legado sanmartiniano porque consiguió acercar la "civilización", y ellos se comprometían, luego de la "dolorosa experiencia" (haciendo referencia al peronismo sin nombrarlo), a "revitalizar la vigencia" de las virtudes de San Martín y "eliminar del cuerpo social los fermentos de demagogia, corrupción, subversión, materialismo y estatismo que aún subsisten". Fiel a la doctrina del ministro de economía, para el gobernador el "estatismo" era sinónimo de "subversión".

\section{Los "centenarios": la llegada de los alemanes, la conquista del Desierto y la generación del Ochenta}

Los funcionarios dictatoriales solían decir: "nosotros somos la Generación del '80, cien años después", negando el laicismo original de sus integrantes y erigiéndose en continuadores del programa liberal, desindustrializador y 
agroexportador del pasado, que cierto sector del gobierno pretendía implementar en el presente. A ese proyecto se le sumaban elementos racistas que despreciaban a las poblaciones aborígenes frente a la inmigración europea. Como parte de la construcción de esta idea de un continuum entre los integrantes del gobierno y la generación del '80, "inventaron” (ANDERSON, 1993; y HOSBAWM y RANGER, 2002) las celebraciones de los "centenarios": la llegada de los primeros inmigrantes alemanes (1978), la conquista del desierto (1979) y la generación del '8o (1980). Estos dos últimos acontecimientos tuvieron una importancia especial, ya que en la organización de los festejos estuvieron involucrados desde el gobernador hasta profesionales de diversos ámbitos nucleados en "comisiones provinciales".

Como dijimos, la llamada generación del '80 estuvo conformada por dirigentes políticos que hacia la década de 1880 promovieron un modelo económico liberal sobre la base de la exportación de materias primas de origen agropecuario -trigo, maíz, lino, carne vacuna y lana- y abierto a la inversión extranjera. De la mano de los inmigrantes y la llegada del ferrocarril, entre 1880 y 1914 la economía argentina creció llegando a convertirse en el tercer exportador mundial de trigo. Sus integrantes defendieron además un sistema democrático restringido en manos de las clases altas, estimularon la inmigración (1876) y sancionaron leyes que se ganaron la oposición de los católicos, como las que establecieron la educación primaria laica (1884), el registro civil (1884) y el matrimonio civil (1888). Ciertamente, los involucrados en los festejos de la dictadura evitaron rememorar públicamente estas tres medidas.

Sobre la inmigración, en 1978 la subsecretaria Dumrauf firmó una directiva dirigida a los maestros de primaria para que se recordaba en todos los establecimientos educativos el centenario de la llegada del "primer contingente de alemanes en cumplimiento de la Ley promulgada por el presidente Avellaneda en 1877". Dicha conmemoración había comenzado en otras provincias el año anterior. El ministro había dispuesto que durante el mes de abril se dictaran dos clases alusivas. (Resolución Ministerial N 268, 14 febrero 1978). En ellas, los docentes tenían que proceder a la lectura y análisis de un documento escrito por el Vicepresidente del Consejo Directivo Central de la Asociación Argentina de los “Alemanes del Volga”, José F. Kamlofski, quien 
residía en San Miguel, provincia de Buenos Aires y cuya sede central estaba en la ciudad de Crespo, provincia de Entre Ríos. El material exponía el proceso histórico que iba desde la emigración de los alemanes a Rusia y la radicación en los márgenes del Río Volga hasta la formación de las colonias en diversas ciudades del país. Con este escrito, las autoridades educativas transmitían a los alumnos bonaerenses que, de todos los grupos de inmigrantes que llegaron para esa época, el más importante para una nación que se definía "blanca" fue el de los alemanes "del Volga". Los alemanes, arios, europeos y asentados mayormente en las provincias del área pampeana, encarnaban el "progreso" y el “avance de la civilización”, tanto para los dirigentes de la generación del '8o del siglo XIX como para los actuales. ${ }^{12}$

Respecto a la celebración del Homenaje al Centenario de la Conquista del Desierto y al General Julio Argentino Roca, el ministro Solari se había adherido a lo dispuesto por el Poder Ejecutivo Nacional, que establecía la fecha conmemorativa del 11 de junio de 1979. De acuerdo a los autores de los textos escolares vigentes, el militar Julio A. Roca, cien años antes, había conquistado por las armas los territorios argentinos de la Patagonia ocupados por indígenas que eran "chilenos" y gracias a esta hazaña, la Argentina, a diferencia del resto de los países de América Latina, estaba conformada por mayoría de población de "raza blanca" y de "origen europeo". (QUINTERO, 1999).

En el ámbito escolar, la Subsecretaría les pedía a los docentes que dieran clases alusivas; organizaran trabajos referidos "al origen de las distintas poblaciones bonaerenses"; hicieran lecciones-paseo "tendientes a identificar lugares históricos relacionados con la conmemoración” y visitaran los Museos Históricos Regionales que "pudieren aportar información al respecto". (C. $\mathrm{N}^{\circ}$ 54, 24 octubre 1978). Sumado a esto, el Departamento de Tecnología Educativa tenía que "promover audiciones radiales referidas al origen de las distintas poblaciones bonaerenses y elaborar series audiovisuales sobre el tema y destinadas a los establecimientos de enseñanza de los distintos niveles”. Junto a la directiva se adjuntaba un Anexo, que era un informe sintético elaborado por la Subsecretaría de Cultura del ministerio bonaerense sobre los sitios de fortines y combates más destacados y las Campañas al Desierto ocurridas

12 Tampoco hay que descartar que este homenaje a los alemanes tenía que ver con las posiciones pro nazis que expresaban varios de los integrantes del gobierno dictatorial. 
exclusivamente en territorio bonaerense.

En febrero de 1979 se creó por decreto una Comisión de Homenaje a la Generación del Ochenta. La Comisión de Homenaje debía "proyectar y realizar el programa de actos conmemorativos a llevar a cabo quedando facultada a esos fines, a percibir contribuciones voluntarias, designar subcomisiones, locales, zonales y municipales"; editar folletos de carácter educativo formativo; organizar en la ciudad de La Plata en la fecha que se designe, durante el año 1980, el acto central de homenaje; y promover un concurso para la "realización de un monumento en la ciudad de La Plata en el lugar que designe la autoridad competente". El ministro le solicitaba a los docentes que incluyeran en los programas de estudio "un más destacado análisis de las obras integrantes y de la importancia de la Generación del Ochenta”. Como ha sido señalado por otros investigadores, el propósito explícito era recrear una continuidad entre esos "preclaros varones que integraron la Generación del Ochenta" y los integrantes de la Junta Militar (SIDICARO, 1996). Se sostenía que en 1880 "no había más civilización que la europea, no había más pensamiento moderno que el procedente del Viejo mundo". El plan de dicha generación transformó a la Argentina "en uno de los países más ricos de América, modelo de progreso y estabilidad". La tercera subsecretaria del ministro Solari, quien era igual que Dumrauf, maestra normal e inspectora de primaria, Olga Cepeda de Ayerra, ordenó que se realizaran en las escuelas, durante todo el año, concursos de monografías, investigaciones, trabajos literarios y dictados de clases alusivas. (C. $\mathrm{N}^{\circ}$ 26, 15 abril 1980). La directiva tenía un Anexo de bibliografía básica sobre el tema y una cronología que iba desde 1876 hasta 1910, año en que "terminaba" la Generación del '8o. En el documento abundaban las referencias a la prosperidad económica y cultural de la época y se habían eliminado de la cronología las sucesivas crisis ocurridas en 1866, 1873, 1890 y 1897 (ROCCHI, 2000). El relato finalizaba en 1910 y con ello evitaban mencionar la sanción de la Ley electoral de 1912 que universalizó el voto masculino (medida, decían, tomada por la "siguiente generación").

\section{Las celebraciones entre 1980 y 1983 : Ejército y Malvinas}

Como dijimos, de las tres fuerzas, fue el Ejército quien siempre predominó 
en el gobierno de la Junta y esto quedó reflejado en el calendario escolar. En 1980 se organizaron dos actividades relacionadas con el Ejército, la primera estuvo vinculada con la sanción de una ley nacional que recordaba que el 29 de mayo de 1980 se cumplían diez años del secuestro y asesinato del ex presidente de facto, teniente general Pedro E. Aramburu, por parte de la agrupación armada del peronismo de izquierda llamada Montoneros. Con ello, buscaban reforzar la asociación entre peronismo y "subversión”. La Subsecretaría ordenó que se dictaran clases alusivas que debían estar a cargo del director y orientadas fundamentalmente "a destacar los valores cívicos del Teniente General Aramburu y su muerte como un intento de avasallar tales valores, exaltando sus virtudes de católico ferviente que le permitió enfrentar la muerte con dignidad de soldado, formado vocacionalmente al servicio de la Patria” (C. $N^{\circ} 36,17$ julio 1980). Para “evitar aviesas interpretaciones” de parte de los docentes, se adjuntaba el texto aprobado por la Comisión Nacional Ejecutiva (Ley 22.166/80).

La segunda conmemoración se organizó a mediados de junio de 1980, cuando la Subsecretaría expresó su adhesión a la Campaña Nacional de Comunicación Social “El niño, la Escuela y el Ejército" para las escuelas primarias. Disponía un conjunto de tareas conducentes a informar a los alumnos sobre la historia del Ejército argentino, sus orígenes y trayectoria, y "desarrollar actitudes que permitieran valorarlo como institución fundamental de la Nación” (C. $\mathrm{N}^{\circ}$ 34, 12 junio 1980). La propuesta era que los docentes organizaran visitas a unidades militares y promovieran la elaboración de trabajos de expresión plástica, actividad práctica o investigación histórica sobre las siguientes temáticas acerca del Ejército: los uniformes a lo largo del tiempo; el servicio a la comunidad; su historia; la acción educativa y cultural; su acción por la libertad y la defensa de la Soberanía territorial. ${ }^{13}$

El año 1981 pasó casi sin conmemoraciones y desde abril de 1982 la rutina escolar se vio interrumpida por la guerra de Malvinas. ${ }^{14}$ El tema Malvinas era un

13 En diciembre de 1978 se habían reformado los contenidos mínimos del ciclo básico del secundario. En septiembre de 1980 se dieron a conocer las nuevas orientaciones para el tercer año de la materia de Historia. El ministro de nación, Llerena Amadeo, anunciaba que el programa estaba adaptado a los "tiempos modernos" y por lo tanto incluía "la agresión y la derrota de la subversión en la Argentina".

14 En julio de 1981 el ministro de educación de ese momento se adhirió a un concurso que tenía el patrocinio del Ministerio de Educación y Cultura de la provincia de Santa Fe. La Empresa SANCOR había organizado un concurso sobre el tema "Conciencia Nacional, influencia en el proceso histórico argentino y de su soberanía; necesidad de su reafirmación”. Del mismo podían 
contenido escolar de vieja data, adonde se argumentaba invariablemente que los derechos de la Argentina sobre las islas eran obvios e indiscutibles (LORENZ, 2006). Se había estipulado que el 10 de junio se recordara en las escuelas que las Islas Malvinas eran argentinas. En 1977 se dispuso por Ley $\mathrm{N}^{\circ} 20561$ que se celebrara el Día de la Reafirmación de Nuestra Soberanía sobre las Islas Malvinas, Islas del Atlántico Sur y Sector Antártico y en 1979, una circular de la Subsecretaría había planteado, a modo de "protesta simbólica contra las agresiones sufridas por la República Argentina en el Sector Austral” que el 10 de junio se hicieran "clases especiales de una hora de duración". El 11 de junio de 1979 se debía llevar a cabo un acto que hiciera referencia a "los antecedentes históricos, la legitimidad de los títulos argentinos" y a la forma en que ella se ejercitaba en el sector austral. Dicho evento debía reflejar en forma clara el "fervor del pueblo argentino por la recuperación de las Islas Malvinas para el patrimonio nacional”. Además, había que embanderar e iluminar todos los edificios escolares y las dependencias oficiales. (C. $\mathrm{N}^{\circ}$ 92, 7 junio 1979).

El 2 de abril de 1982 las tropas argentinas invadieron las Islas Malvinas y le declararon la guerra a Gran Bretaña (PALERMO, 2007). Un día después el cuarto ministro, Julio Lascano, dio instrucciones para que se dictaran clases alusivas en todas las escuelas bonaerenses. Según se decía a través de la prensa, se había vivido "una jornada altamente emotiva en todas las escuelas bonaerenses a raíz de la recuperación de las Islas Malvinas, Georgias y Sandwich del Atlántico Sur". En todos los establecimientos se hizo "hincapié sobre la justicia estricta" que implicaba el hecho de la recuperación de aquello que "siempre formó parte de nuestro patrimonio nacional", aclarando que a partir de ahora el 2 de abril de 1982 pasaría a ocupar un lugar prominente en el Calendario Escolar, “junto a los más caros a nuestra nacionalidad, por lo cual tendrá para todos la misma importancia que el 25 de mayo, el 9 de julio y las demás fechas patrias". A los pocos días se dictaminó que todos los establecimientos de la provincia tenían que poner el nombre de "Islas Malvinas" a una de sus aulas. Posteriormente, instructores de Defensa Civil capacitaron a los maestros para saber qué hacer en caso de "emergencia bélica".

En el medio de la guerra, decidieron homenajear especialmente a la

participar los alumnos de cuarto y quinto año de las escuelas de Educación Media y los alumnos de Institutos Superiores de todo el país. 
Armada. En mayo se solicitaba a los docentes que ese Día de la Armada (17) se recordara de manera "diferente". Se sugería hacer un alto en las tareas docentes y escolares habituales para rendir un "cabal homenaje a nuestra Armada". En dicha fecha se debía dedicar una hora a fin de reseñar las acciones cumplidas desde el día 2 de abril, "poniéndose particular énfasis en destacar que lo realizado por dicha Fuerza constituye la prolongación de una línea histórica que nace con Guillermo Brown, Hipólito Bouchaurd, Juan Baustista Azopardo y Tomás Espora”. (C. Nº 9, 14 mayo 1982). En la circular se adjuntaba un Anexo que debía leerse en las escuelas para recordar que en vistas de la "etapa de gloria que se ha iniciado y continúa desarrollándose", adonde los nombres del "capitán de Fragata Pedro Edgardo Giachino y del Crucero A.R.A. General Belgrano” ya habían ingresado "en la mejor historia de nuestra Patria". A principios de junio llegó a la Argentina el Papa Juan Pablo II y el ministro Julio Lascano estimaba conveniente disponer el dictado de clases alusivas en todos los establecimientos sobre la significación histórica del acontecimiento que se vivía, marcando el privilegio que significaba para la Argentina la presencia papal, reconociendo al país como heredero de la más "genuina civilización occidental".

La guerra finalizó en junio de 1982, cuando los militares argentinos presentaron su rendición. En julio el ministro propuso que se realizaran "actos patrióticos" en las escuelas de toda la provincia en homenaje a los combatientes que habían regresado del Atlántico Sur. En cada establecimiento debían convocarlos, para reconocerles el deber cumplido, y darles la bienvenida a sus "nuevos puestos de responsabilidad en la sociedad". Frente a la derrota y el creciente desprestigio de la Junta, las autoridades bonaerenses creían necesario continuar con el discurso de defensa de la soberanía. El ministro Lascano organizó una "campaña" llamada "carta de un niño al mundo". Estaba dirigida a las escuelas primarias "en virtud de la cual los escolares escribirán cartas a instituciones y organismos internacionales y a distintas personalidades del mundo para hacer conocer la posición argentina con respecto a sus derechos de soberanía sobre las Malvinas y demás islas del Atlántico Sur”. Los niños escribirían "una carta por día" en la clase de Lengua con el objetivo de "dar a conocer a través de ellas la verdad histórica política y geográfica”. Las cartas serían enviadas y pagadas por los padres de los alumnos porque el Ministerio no podía hacerse cargo de los gastos. 


\section{Reflexiones finales}

En este artículo analizamos qué hechos y personajes fueron incluidos y excluidos del relato histórico escolar, qué usos del pasado se hicieron, con qué tipo de organizaciones estaba vinculado el ministro y cuáles acciones debían realizar los docentes. Vimos que estos cambios se inscribían dentro de un programa más amplio de la dictadura militar que se proponía reestructurar la economía, desmantelar el Estado interventor montado por el peronismo y disciplinar autoritariamente a la población. Para poder llevarlo a cabo, los militares contaron con el apoyo estratégico de la Iglesia católica y de varias organizaciones que le eran afines ideológicamente y que aceptaron intervenir en el sistema público de enseñanza.

Respecto al calendario mostramos que, en una operación que estaba lejos de ser novedosa, los encargados del área en 1976 se ocuparon de borrar y de calificar negativamente cualquier material escolar que tuviera relación con Perón, el peronismo y la supuesta defensa de los caudillos federales. El calendario no volvió a sufrir mayores modificaciones hasta el fin de la dictadura. Las conmemoraciones en cambio, mostraban una dinámica diferente e ilustraban las preocupaciones del gobierno dictatorial en los distintos momentos y sus intentos de legitimarse en el poder. Los funcionarios seleccionaron arbitrariamente sucesos del pasado y los resignificaron según sus necesidades más inmediatas. Durante todo el año 1978 los integrantes de la Junta Militar recibieron denuncias de parte de las organizaciones de derechos humanos en el exterior, lo que los llevó a organizar varias actividades que buscaban que los alumnos "adoptaran actitudes positivas de adhesión al Proceso", según rezaba el documento de la SIP. Los estudiantes en las aulas debían valorar el "sacrificio" que los militares estaban realizando para erradicar la subversión en defensa de la familia, el estilo de vida y la esencialidad de la Nación. Además de las denuncias del "terrorismo internacional", había dos cuestiones más que atender: la inflación que generaba la política económica del ministro y el conflicto con Chile. Con motivo del bicentenario del nacimiento de San Martín, se les decía a los alumnos que debían evitar quejarse por el aumento de los precios y a propósito del Día de la Tradición y la Soberanía Nacional, que gracias a la presencia de los militares en el poder los chilenos no podrían "invadir" la zona sur. 
Del lado de los docentes, señalamos que fueron vistos como portavoces privilegiados del régimen. Se les pidió que dieran clases alusivas, trabajaran en el aula los documentos elaborados por diferentes organizaciones públicas y privadas, llevaran a los alumnos a museos, organizaran concursos, y/o decoraran las escuelas y comercios con frases preestablecidas. La conformación de comisiones provinciales para determinados eventos (San Martín, conquista del desierto y generación del '80) presididas por el gobernador o algún ministro e integradas por personalidades reconocidas de la comunidad, hacía que la responsabilidad de la conmemoración en ocasiones trascendiera las paredes de las aulas y se extendiera a los demás actores de la sociedad.

Por otra parte, los dirigentes se autodenominaron continuadores de la generación del ' 80 , establecieron que había empezado en 1876, y como aquella, le otorgaron a la escuela un lugar central y fundacional. Si bien se decían sus herederos, evitaron hacer público su laicismo y a través de su recuerdo exaltaron el rol del Ejército, la legitimidad del uso de la violencia hacia el "enemigo interno" conformado en el pasado por los "indios" y "caudillos", y en la actualidad, por la "guerrilla apátrida". La idea de "progreso", igual que antes, se encontraba ligada a lo europeo y particularmente a lo alemán. Asimismo, buscaban que los alumnos valorizaran el sistema político de fines del siglo pasado que sostenía el principio de exclusión de la mayoría de los hombres y de la totalidad de las mujeres. En suma, gracias al Ejército la nación era católica, civilizada y "blanca". El mensaje último era que los militares y su programa económico, cien años después, harían de la Argentina uno de los países más ricos de América y re fundarían la nación. Inmediatamente después de la formulación de estas promesas de revivir un pasado glorioso, en 1981 las autoridades educativas guardaron un silencio casi absoluto. En 1982 las celebraciones durante los primeros meses estuvieron ligadas a la guerra de Malvinas y habían recobrado algo del optimismo de la etapa anterior, aunque duraron muy poco tiempo. Luego de la derrota, en el medio de un clima social y político que había cambiado rotundamente, ya nadie volvió a ocuparse de comunicar algo a través del calendario. 


\section{Bibliografía}

AMÉZOLA, Gonzalo de. Esquizohistoria. La Historia que se enseña en la escuela, la que preocupa a los historiadores y una renovación posible de la historia escolar. Buenos Aires: Libros del Zorzal, 2008.

El pasado servicial. Elementos revisionistas en los textos de Cultura Ciudadana (1952-1955), Clío \& Asociados n 1, Buenos Aires, 1996, pp. 43- 57.

ANDERSON, Benedict. Comunidades imaginadas. Reflexiones sobre el origen y la difusión del nacionalismo. México: Fondo de Cultura Económica, 1993.

ALONSO, Fabiana. Nacionalismo y catolicismo en la educación pública santafesina (1976-1983), Prohistoria. Año XI, N 11, Rosario, 2007, pp. 107-124.

AVELLANEDA, Andrés. Censura, autoritarismo y cultura. Argentina 19601983/1. Buenos Aires: CEAL, 1986.

BERTONI, Lilia Ana. Patriotas, cosmopolitas y nacionalistas. La construcción de la nacionalidad argentina a fines del siglo XIX. Buenos Aires: Fondo de Cultura Económica, 2001.

CARRETERO, Mario. Documentos de identidad: La construcción de la memoria histórica en un mundo global. Buenos Aires: Paidós, 2007.

CATTARUZA, Alejandro. El revisionismo: itinerarios de cuatro décadas. IN: CATTARUZZA, Alejandro y EUJANIAN, Alejandro. Políticas de la historia. Argentina 1960-1960. Buenos Aires: Alianza, 2003.

FERRO, Marc. Cómo se cuenta la historia a los niños en el mundo entero. Buenos Aires: Fondo de Cultura Económica, 1981.

FILC, Judith. Entre el parentesco y la política. Buenos Aires: Biblos, 1997.

FRANCO, Marina y LEVÍN, Florencia (comp.). Historia reciente. Perspectivas y desafíos para un campo en construcción. Buenos Aires: Paidós, 2007.

HALPERÍN DONGHI, Tulio. El revisionismo argentino Buenos Aires: Siglo Veintiuno, 1971.

HOBSBAWN, Eric y RANGER Terence (eds.) La invención de la tradición. Barcelona: Crítica, 2002.

INVERNIZZI, Hernán y GOCIOL, Judith. Un golpe a los libros. Represión a la cultura durante la última dictadura militar. Buenos Aires: EUDEBA, 2002.

KAUFMANN, Carolina. Los manuales de civismo en la historia reciente: huellas y señales. IN: KAUFMANN, Carolina (dir.). Dictadura y Educación. Los textos escolares en la historia argentina reciente Buenos Aires, Miño y Dávila/ UNER, 2006, pp.149-202.

KAUFMANN, Carolina y DOVAL, Delfina. La enseñanza encubierta de la religión: la Formación Moral y Cívica. IN: KAUFMANN, Carolina (dir.). Dictadura y Educación. Los textos escolares en la historia argentina reciente Buenos Aires, Miño y Dávila/ UNER, 2006, pp. 203-224.

LORENZ, Federico. Las guerras por Malvinas. Buenos Aires: Edhasa, 2006.

MCGEE DEUTSCH, Sandra. Contrarrevolución en la argentina. 190o-1932. La Liga Patriótica Argentina. Bernal: Universidad Nacional de Quilmes, 2003. 
OBREGÓN, Martín. Entre la cruz y la espada. La Iglesia católica durante los primeros años del "Proceso". Bernal: Universidad Nacional de Quilmes, 2005.

PLOTKIN, Mariano. La Fundación Eva Perón o el largo brazo del Régimen. IN: Mañana es San Perón. Buenos Aires: Sudamericana, 1994.

PRIVITELLIO, Luciano de. Los textos de Civismo: la construcción del argentino ideal. IN: ROMERO, Luis A., (coord.) La Argentina en la escuela. La idea de nación en los textos escolares. Buenos Aires: Siglo Veintiuno, 2004.

QUATTROCCHI-WOISSON, Diana. (1995). Los males de la memoria. Historia y política en la Argentina. Buenos Aires: Emecé, 1995.

QUINTERO, Silvina. El país que nos contaron. La visión de Argentina en los manuales de Geografía (1950-1997), Entrepasados nº 16, 1999.

. Los textos de Geografía: un territorio para la nación. IN: ROMERO, Luis A. (coord.) La Argentina en la escuela. La idea de nación en los textos escolares. Buenos Aires: Siglo Veintiuno, 2004.

PALERMO, Vicente. Sal en las heridas. Las Malvinas en la cultura argentina contemporánea. Buenos Aires: Sudamericana, 2007.

ROCCHI, Fernando. El péndulo de la riqueza. La economía argentina en el período 1880- 1916. IN: Nueva Historia Argentina. El progreso, la Modernización y sus Límites (1880-1916) Buenos Aires: Sudamericana, 2000, pp. 15-69.

RODRÍGUEZ, Laura Graciela. Gobierno municipal, descentralización educativa y funcionarios en la provincia de Buenos Aires durante la dictadura militar. IN: BOHOSLAVSKY, Ernesto y SOPRANO, Germán (eds.). Un Estado con rostro humano. Funcionarios e instituciones estatales en la Argentina (188o a la actualidad). Los Polvorines: Universidad Nacional de General Sarmiento (en prensa).

y SOPRANO, Germán. La política universitaria de la dictadura militar en la argentina: proyectos de reestructuración del sistema de educación superior (1976-1983). En Nuevos Mundos. Mundos Nuevos. París, <http://mundosnuevos.revues.org>, 2009a.

ROMERO, Luis Alberto Los textos de Historia: el relato del pasado. IN: ROMERO, Luis A. (coord.) La Argentina en la escuela. La idea de nación en los textos escolares. Buenos Aires: Siglo Veintiuno, 2004.

SIDICARO, Ricardo. El régimen autoritario de 1976: refundación frustrada y contrarrevolución exitosa. IN: QUIROGA, Hugo y TCACH, César (comps.) A veinte años del golpe. Con memoria democrática. Rosario: Homo Sapiens Ediciones, 1996, pp. 9- 26.

SCHVARZER, Jorge. La política económica de Martínez de Hoz. Buenos Aires: Hypamérica, 1986.

SVAMPA, Maristella. El dilema argentino: Civilización o barbarie. De Sarmiento al revisionismo peronista. Buenos Aires: El Cielo por Asalto, 1994.

VALLS, Rafael. La enseñanza de la Historia y textos escolares. Buenos Aires: Libros del Zorzal, 2008.

VERBITSKY, Horacio. Doble Juego. La Argentina Católica y Militar. Buenos 
Laura Graciela Rodriguez

La Historia que debía enseñarse durante la última dictadura militar en Argentina (1976-1983)

Aires: Sudamericana, 2006.

Colaboração recebida em 17/03/2009 e aprovada em 17/05/2009. 